\title{
VIEIRA, Patrícia, Portuguese Film, 1930-1960: The Staging of the New State Regime
}

New York / London: Bloomsbury, 2013, 262 pp.

Sérgio Guimarães de Sousa*

spgsousa@ilch.uminho.pt

Sempre que está em pauta investigar a cosmovisão sociopolítica do Estado Novo, as fontes de análise privilegiadas provêm em geral, como seria de resto expectável, de material escrito (discursos, legislação, entrevistas, ensaios, livros, etc.). Há, porém, quem, não descartando, como é evidente, a relevância dessas fontes, seja capaz, como é o caso muito notório deste estudo, de abordar, com rigor e pertinência, os diversos polos que perfazem a mundividência estadonovista a partir de uma outra perspetiva não menos reveladora da sociedade de então: a multifacetada perspetiva do cinema. E não por acaso, as análises baseadas na filmografia tendem de há uns anos a esta parte a adquirirem uma centralidade em qualquer refle- xão em torno da Ditadura. Porque, como sabemos, esta não descurou o poder representacional das inovações formais proporcionadas pelo discurso audiovisual. Por outras palavras, o cinema, nas suas diversas modalidades (cinema de propaganda, filmes históricos ou sobre o império colonial, etc.), irrompe enquanto filiação do regime. E o que o estudo de Patrícia Vieira ${ }^{[1]}$ se propõe fazer consiste precisamente em analisar os mecanismos de afiliação do cinema dessa época, condição para compreender as bases pelas quais se estrutura a lógica do regime no campo cinematográfico. E a partir daí entender os efeitos ideológicos que o cinema estadonovista, concebido como um hino identitário, foi capaz de induzir no

Departamento de Estudos Portugueses e Lusófonos, Universidade do Minho, Braga, Portugal.

[1] Numa primeira edição, em português: Cinema no Estado Novo: A Encenação do Regime, Lisboa: Colibri, 2011. 
público: "In this study we looked at the cinematic reproduction of Salazarist ideology and at the portrayal of New State mythology and value in film. One of the tasks facing Portuguese society today is to undertake a thorough examination of the ideals of the regime. This book aims to contribute to the ongoing process of de-idealizing the emblematic heroes of Salazarism by analyzing their depiction in film" (p. 236).

Sendo o cinema o discurso no interior do qual os valores sociais politicamente preconizados se podem afirmar com mais ênfase, caberia, por assim dizer, messianicamente à cinematografia lusa, elevada ao estatuto de indústria, concentrar-se naquilo que (supostamente) definiria a realidade portuguesa, enfatizando os ideologemas dessa realidade unívoca (sonegando, claro, a faceta sinistra do regime); e, em consequência, repudiar sem concessões como espúrio (digamos) tudo o que lhe fosse estranho, por forma a evitar contaminações indesejáveis (estranheza ramificada em aspectos como a modernidade simbolizada pela cidade, a emancipação feminina, o pensamento crítico, e por aí fora, aspectos sintomaticamente reduzidos de modo a deles não restar senão uma ideia nefasta em nome de um cinema que perfilha uma visão crítica do mundo moderno).

Se em Portugal (sejamos justos) a intervenção do Estado não foi em boa verdade tão drástica como na Alemanha nazi, na Itália fascista ou mesmo na Espanha franquista, não menos certo é o facto de o regime ter atuado sem complexos nem restrições. O discurso cinematográfico, com efeito, padeceu de apertada censura, afora a constrição não pouco despicienda de somente as obras consentâneas com o ideário estadonovista merecerem subvenção estatal ( $c f$. p. 8 e ss.). Só assim, aliás, se percebe que as comédias, onde sobressaía um país pobre, porém alegre e, mais, alegremente regido por um estrutura social antemoderna, não só não refletissem a situação nacional como igualmente rasurassem, como se ser português fosse pertencer a outro planeta, a internacional (o apogeu das comédias, onde não se fala de convulsões bélicas, coincidiu com a II Grande Guerra, recorde-se), distorcendo a representação da realidade ( $c f$. p. 13).

No primeiro capítulo, "Propaganda in the New State: The May Revolution (A Revolução de Maio)", a A. procura dilucidar as diferentes acepções existentes em torno do conceito de propaganda, contrapondo a de Salazar (propaganda como meio para divulgar a verdade) à do seu propagandista-mor, António Ferro (a propaganda enquanto versão ideal da realidade). Mas este capítulo inicial procura em especial analisar com atenção os expedientes 
empregues em prol da persuasão ideológica no filme A Revolução de Maio. Como é o caso da intercalação no seio da trama ficcional de imagens documentais, com uma estratégia clara: "Documentary footage forms a bridge between fact and fiction, and in this process it undergoes a double inversion. The documentary scenes, a version of real events, are first fictionalized through their inclusion in the filmic narrative, and then reintroduced into the world by the power of art, in order to be disseminated in society. The result of this mutation is a transfiguration of reality itself, which should adapt to the model put forth by the movie" (p. 35). Neste sentido, afigura-se particularmente relevante o recenseamento que P. Vieira faz das técnicas de encenação através das quais o documentário enaltece a figura de Salazar de modo a instigar a identificação da figura do líder com o povo. Leia-se: "the dictator should feel like he is part of the people, and more importantly, the people should feel like they are the dictator, which will only happen if the dictactor becomes the people and the people becomes dictator, albeit only transiently" (p. 38). Nada que o cinema alemão de Leni Riefenstahl, em Der Sieg des Glaubens e em Triumph des Willens, não ensinasse já ( $c f$. p. 40).

O segundo capítulo, "Poets on the Screen: Bocage, Camões, and the Heroes of the Regime", visa estudar dois filmes de Leitão de Barros Bocage e Camóes - e neles rastrear o modo como se operacionaliza a intenção de António Ferro de se servir da literatura nacional, entendida como valor patrimonial a cultivar, sendo as grandes figuras dessa literatura, declinadas em versão nacionalista e patriótica, dignas da condição de heróis. Ou, como competentemente sustenta a A., o que se fez foi realizar os filmes a partir de uma cadeia metonímica cujo ponto culminante consistiu na representação dos autores e da sua vida. Obra e biografia seriam desta forma coextensíveis; e isso de tal maneira que esta faria as vezes daquela. Segundo esta perspetiva biografista, com a qual a obra se lê pelo monóculo da vida, ilustradora do legado (pós) romântico no Estado Novo, aquela reduz-se metonimicamente a pouco mais não ser do que uma súmula de episódio conhecidos da biografia dos poetas (e não forçosamente fidedignos). De outro modo: estes, no ecrã, adquirem a centralidade de heróis individuais ( $c f$. p. 62-63). E como seria de esperar, o Estado Novo cedeu bem depressa à tentação de mitificar Camões (e não apenas) em função do seu ideário. Camões foi, com recurso a alguma sofisticação estética, (re)visto, ou melhor, dado a (re)ver, como herói da pátria, ratificando significados políticoideológicos. E o cume do heroísmo estaria, evidentemente, reservado à 
figura de Salazar, o herói dos heróis. Curiosamente, Camões e Bocage, como aponta com inteira justeza a A., não encaixam sem falha no perfil delineado pelo Estado Novo.

O problema está em que figuras como a destes poetas (exemplos suficientes do artista marginal, quer dizer, avesso à ordem social e às constrições cívicas, castradoras do seu irreprimível ímpeto sentimental) significam na verdade também o que mais receia o regime: volubilidade amorosa, que é como quem diz, o ascendente das emoções sobre a sábia razão. O que não é sem dificultar a apropriação simbólica. Em conformidade com o salazarismo, como esclarece a dado momento P. Vieira, "The excessive sentimentality and lack of tenacity of the Portuguese led to national decline, in the same way that Camões's and Bocage's romantic fickleness caused them countless troubles, despite stimulating their poetic creation" ( $\mathrm{p}$. 69). A solução passou por o cinema aproveitar esse lado menos razoável de Camões e Bocage para admoestar a presumível predisposição leviana e inconstante do povo português. $\mathrm{O}$ intuito pedagógico-moralizador adivinha-se sem dificuldade: reforçar a fidelidade aos credos cívicos e ideológicos propalados pelo Estado ( $c f$. p. 71). Credos superiormente corporificados por Salazar, intérprete de verdades sobre as quais se erigiria a nação portuguesa ( $c f$. p. 83).
Quanto ao terceiro capítulo, "Rural Life in Cinema: In Defense of a Natural Society", concentra o essencial da sua atenção nos chamados 'filmes regionais ou folclóricos', o mesmo é dizer, aqueles filmes, hoje perfeitamente historicizáveis como etnográficos, não obstante tratarem-se de versões edulcoradas da vida campestre, contextualizados no universo rural tão caro a Salazar. De que modo se relacionam tais filmes com o salazarismo? Traduzem, à custa de uma idealizada imagem do campo como locus amoenus, a apologia de uma salutar sociedade natural. No mundo rural persistiria, pois, um edificante espírito comunitário em flagrante contraste com esse lugar de perdição, porque associado às paixões funestas e aos desvarios, que dá pelo nome de cidade. O campo, numa palavra, seria o espaço por excelência, a bem do reaportuguesamento de Portugal, onde se tornaria possível, e sobretudo desejável, repudiar com ênfase as vicissitudes da urbe e decalcar a vida da nação da (imutável) natureza. Veja-se: "it was appropriate for New State films dealing with the rural world to highlight its advantages over urban culture, to reproduce natural rhythms, and to avoid artificiality. This movie's educational and propagandistic value is derived precisely from their faithful representation of rural life, a social model for all Portuguese people" (p. 82). 
O quarto capítulo, "The Miracle of Salazarism: Fátima, Land of Faith (Fátima, Terra de Fé)", incide sobre a dicotomia fé / razão, presente no debate referente ao fenómeno das aparições fatimitas e que se arrastava desde a Primeira República. Com o filme Fátima, Terra de Fé, o regime propôs-se como que encerrar a discussão, propondo uma hábil conjugação das duas posturas, evitando antagonismos drásticos. Convirá neste ponto ter em mente o seguinte: "The New State, which is presented as an alternative to Republicanism, is suited to the national situation, since it is the political expression of the harmony of reason and faith" (p. 134). O que estava em jogo, como muito bem salienta ainda P. Vieira, consistia no receio do niilismo, visto por Salazar como a antecâmara do comunismo (cf. 137-143).

O quinto capítulo, "Gender Stereotypes in New State Cinema", aborda a questão da imagem da mulher na filmografia estadonovista. O cinema tratou, claro está, de exaltar o lugar, bem subalterno, a que o regime (patriarcal na essência) restringia a condição feminina. Mulher louvável seria a esposa exemplar e, por extensão, a mãe de família impecável. Resultou daqui a desvalorização, senão mesmo a extrema marginalização, das mulheres emancipadas. $\mathrm{O}$ que se constata no destino pernicioso (ostracismo, exílio) ou até trágico (a morte) reservado nos filmes às mulheres insubmissas ao modelo de dominação masculina. Como foi seguramente o caso das fadistas (dir-se-iam o reverso obsceno da virtuosa camponesa). Tanto mais que em não poucos fados sobressai a expressão do sofrimento enquanto prazer masoquista, sendo esse gozo dificilmente articulável com crenças e expectativas ancoradas nas ideias de trabalho, moderação e perseverança, como se percebe sem custo (cf.p. 166).

O sexto capítulo, "The Empire as Fetisch: Spell of the Empire (Feitiço do império)", aquele que me parece ser o capítulo culminante do livro, com base na leitura que faz de Feitiço do Império (António Lopes Ribeiro), oferece-nos a visão ultramarina do regime. Uma visão em que as ordens teórica e cultural se acham imbuídas de ideologia imperial. Ou seja, Portugal como, digamos, substância nacional coextensível às colónias (e supostamente a bem da paz perpétua e do progresso irrestrito dessas colónias); e, assim sendo, a perspetivação da nação como realidade robusta com legitimidade para reivindicar um lugar no mundo. E esse lugar destacável no mundo (e, em rigor, do mundo) seria amplamente justificado por essa monumental territorialidade de referência com o nome de colónias, o que não estaria ao alcance de nenhuma outra 
nação. Colónias essas alvo, por isso, de uma compreensível visão fetichizada, conforme sustenta com perspicácia a A., socorrendo-se, e bem, de Freud. Quer dizer, as colónias, com os seus territórios até certo ponto (o do olhar luso, em particular aquele acostumado a tudo contemplar a partir da remota aldeia) incomensuráveis, cada qual com as suas etnicidades, funcionariam na proporção de uma compensação, tal como acontece na lógica do fetiche. Significou isto, em termos práticos, que as decisões adoptadas relativamente às colónias "were based upon a virtual empire, an illusory object conceived as a caricature of reality. In other words, what was at stake was not something concrete and palpable, but rather a fetish created by the fetishist's fantasy as a replacement for the lost object" (p. 186).

E compreende-se sem dificuldade a razão de semelhante atitude: "What is at stake here is Portugal itself, whose aspiration of becoming a powerful nation in economic and political terms depended, [...], on the colonies. Losing the overseas empire would mean losing the country itself, i.e., renouncing the conception of the nation that the New State disseminated. The overseas territories supplemented the mainland and sustained an image of a country that did not really exist. Using freudian terminology, the colonial empire functioned as a fetish. The colonies simultaneously hid and revealed the regime's inability to produce a nation that corresponded to the magnificent idea of Portugal created in its leader's speeches. The angst associated with the loss of the overseas possessions can therefore be explained by a fetishist fear of ruining this vision of the country and, consequently, the national project outlined by the New State" (p. 183). Portanto, através das colónias Portugal compensaria (ilusoriamente) a sua insignificância geopolítica no concerto das nações desenvolvidas, daí o receio imenso de carecer delas. "Without the empire-fetish, the New State" - como escreve P. Vieira - "would be forced to acknowledge the reverse side of its nationalism and face a suddenly emasculed Portugal, which would not have a penis, the attribute of other bigger and stronger countries. Salazarism's phallogocentric discourse, inherited from centuries of imperialism, could not survive this reduction of Portugal to its true dimensions" (p. 184). E o cinema, instrumento de propaganda privilegiado, conforme assinala a A. em Feitiço do Império, refletiu exemplarmente a fetichização do império (seja-me concedido, já agora, um parêntesis para notar, dada a pertinência hermenêutica revelada por P. Vieira no uso do registo psicanalítico, que talvez não tivesse sido irrelevante operar psicanaliticamente a uma escala menos 
reduzida. Isto é, talvez se revelasse pertinente acrescentar, pelo menos, o contributo lacaniano. O que permitiria a compaginação da figura de Salazar com a possibilidade operativa de um conceito como o Nomedo-Pai, por exemplo).

O sétimo e último capítulo, "The Spirit of the Empire in Chaimite", debruça-se sobre a ênfase, como forma de consolidação política, concedida por Salazar à noção de espírito. Quer dizer, à presunção de uma superioridade moral, a qual o ditador pretendia exportar para África. Noutros termos, ao invés da ganância materialista, o que se apregoava era a prevalência de uma realidade espiritual sob a forma de superioridade moral através da qual os portugueses seriam capazes de superarem os povos confinados ao condenável materialismo. Nesta força espiritual residiria a possível aglutinação hegemónica dos diversos povos do império sob uma mesma - e intransigente - orientação.

Concluindo, o estudo de P. Vieira, cuidadosamente conduzido do ponto de vista metodológico, por partir da análise rigorosa do contexto e não se abster de recorrer a documentação histórica, estudo assente numa progressão argumentativa sólida e, logo, eficaz e, é preciso também realçar, baseado num corpus, ainda que um tanto restrito, bem escolhido, constitui, a vários títulos, uma investigação digna da maior relevância. Desde logo porque se boa parte do que nele se lê seria presumível - ninguém duvidará, creio eu, da vertente ideológica do cinema sob a égide do Estado Novo -, a verdade é que se trata de uma abordagem capaz de aprofundar, por vezes bem decisivamente, os meandros, incluindo os menos explícitos, dessa ideologização da sétima arte. E ainda porque se trata de um estudo que vem mostrar o que talvez não soubéssemos com tanta clareza: que se no Estado Novo o cinema e a ideologia em vigor caminharam sempre lado a lado, isso aconteceu mesmo (ou talvez sobretudo) quando o regime caminhava já sob visíveis ruínas. $\mathrm{E}$ reconheça-se que P. Vieira não se limitou a teorizar. $\mathrm{Na}$ especificidade da relação entre Ditadura e cinema, a A. soube com inteligência cruzar saberes e propostas de leitura convincentemente argumentadas a cada passo e não raro clarividentes. Ou seja, não há como não ver em Portuguese Film, 1930-1960: The Staging of the New State Regime a concretização assaz competente, porque informada e muito capaz do ponto de vista exegético, de um trabalho de referência no domínio da História e no dos estudos cinematográficos. 
